\title{
Geometry and Proportions of the Traditional Trulli of Alberobello
}

\author{
Leonardo Todisco ${ }^{1}$ (D) Giuseppe Sanitate ${ }^{2} \cdot$ \\ Giuseppe Lacorte ${ }^{3}$
}

\begin{abstract}
The Valle d'Itria area is characterised by the presence of dry stone vernacular structures called 'trulli'. Although these represent a unique example of complex vernacular architecture, an in-depth analysis of their geometric features has not been carried out. This paper aims to fill that gap, and includes a review of their historical origin and a description of their most common building typologies. The building technique is reviewed in all its stages in order to point out the important relation between construction, structural behaviour and final shape of the building. Furthermore, morphologies and proportions of 30 existing trulli are investigated, by means of virtual three-dimensional models obtained by a combination of laserscanner and geo-radar surveying. The high-fidelity geometric models offer a new interpretation of their architecture. Moreover, this study highlights the lack of a systematic and consistent building methodology of trulli.
\end{abstract}

Leonardo Todisco

lt@he-upm.com

Giuseppe Sanitate

gs528@eng.cam.ac.uk

Giuseppe Lacorte

giuseppe.lacorte@alice.it

1 Universidad Politécnica de Madrid, Prof. Aranguren s/n, 28040 Madrid, Spain

2 Cambridge University, Trumpington Street, CB2 1PZ Cambridge, UK

3 Via Taranto, n.77/B, 74023 Grottaglie, Italy 


\section{Introduction}

Trulli (singular, trullo) are a vernacular dry-stone building typology found in the Valle d'Itria, located in the central area of Italy's Apulia region (Fig. 1). Besides being used as deposits for agricultural tools and as animal shelters, trulli have been employed as a residential solution in both the past and present (Ambrosi et al. 1997). There is no clear agreement about the origin of trulli, but legend has it that they were built without mortar in order to be promptly dismantled and to allow local farmers to avoid paying taxes for their temporary houses.

Dry-stone buildings are commonly spread in rural areas throughout Italy, usually in the form of temporary constructions used by farmers and shepherds. In contrast, due to their prolonged usage and architectural complexity, trulli are unique and observed only in this part of the Italian peninsula. The trullaro, or master builder, is the technician who handles the intricate construction process of a trullo, which starts with the cutting of stones and ends with the erection of the corbelled dome. On the basis of his experience, the master builder combines the dual role of architect and engineer. He assigns the thickness and height of the basement wall and the type, size and shape of the stones according to their location in the structure; he designs the archways for doors and windows; he determines the complex geometry of the superimposed dome.

In 2014 we created the Apuliabase project (www.apuliabase.com) and suggested a procedure for their preliminary assessment, with the aim of creating a database that may serve as decisional tool for their conservation (Sanitate et al. 2014). This procedure does not provide an absolute value of the structural capacity, but it gives an understanding of the relative safety of each structure within a specific set of trulli. The main outcome of the project is a database (www.database.apuliabase.com) that envisages the support of the public institutions in charge for the conservation of the architectural heritage. The database provides tangible criteria for coordinating

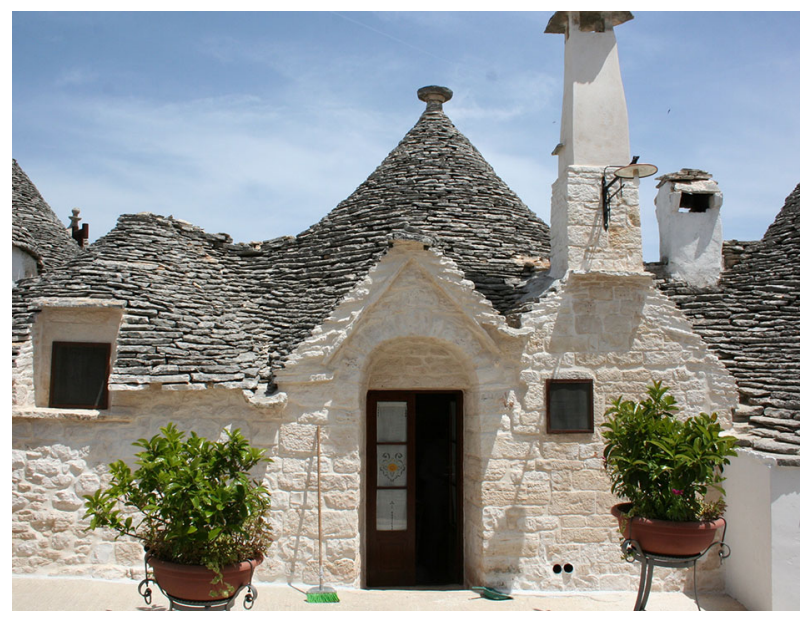

Fig. 1 Photo of a typical trullo located in the historical centre of Alberobello (Apulia) 
funding for the retrofitting of a given set of trulli. This approach has been applied by the authors to evaluate the structural vulnerability of thirty existing trulli spread through the town and surrounding countryside of Alberobello (Figs. 2, 3).

It is recognised that the structural safety of masonry structures is strongly related to their geometry (Heyman 1995; Huerta-Fernández 2008); for this reason detailed survey techniques were employed for obtaining high-fidelity geometric models of trulli. The objective was to characterise a section of the case studies in terms of

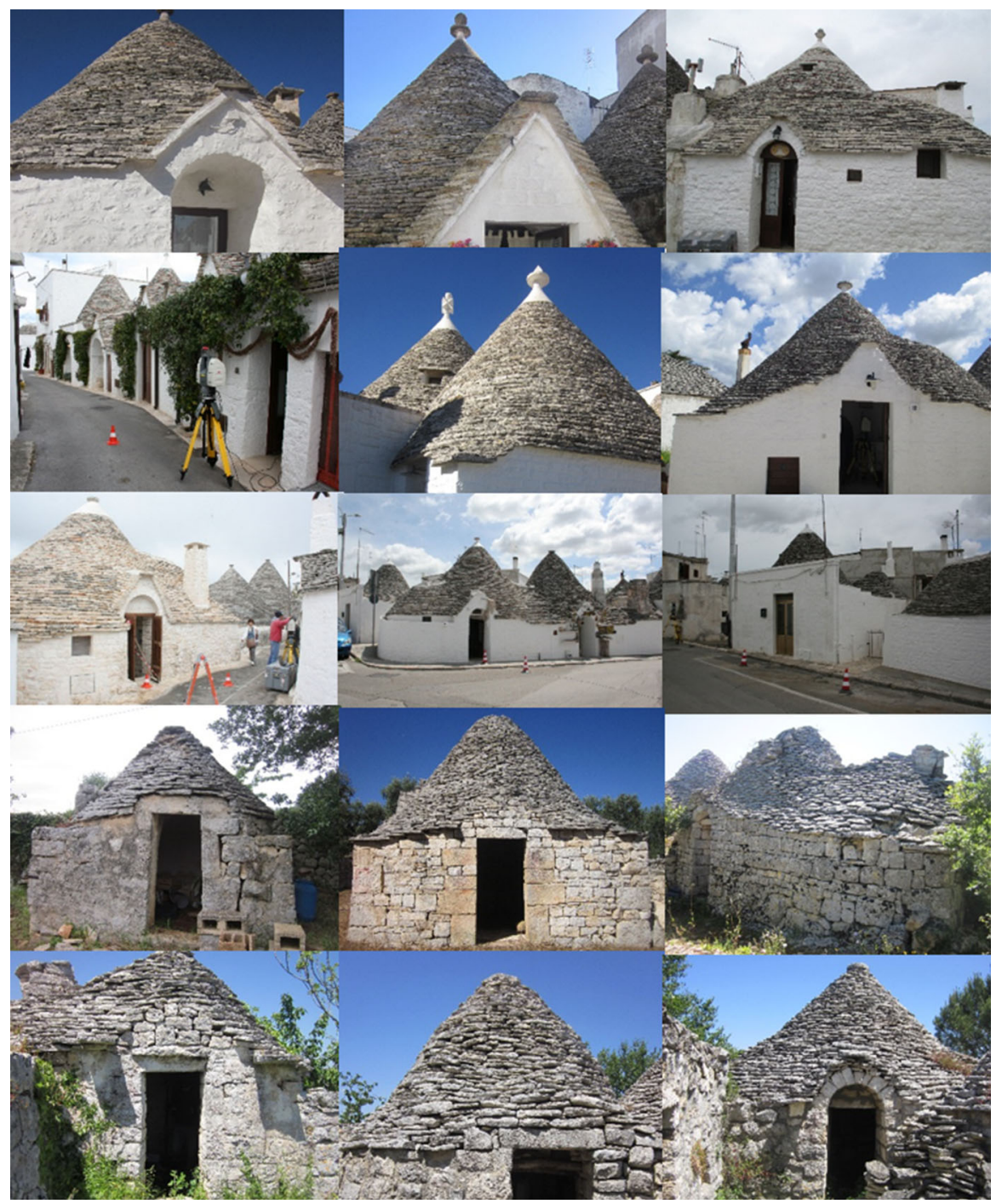

Fig. 2 An overview of the case studies (one of two) considered in the Apuliabase Project. The case studies belong to a wide range in terms of preservation conditions; both well-preserved and crumbling trulli were considered within the city centre (Alberobello) and its countryside 


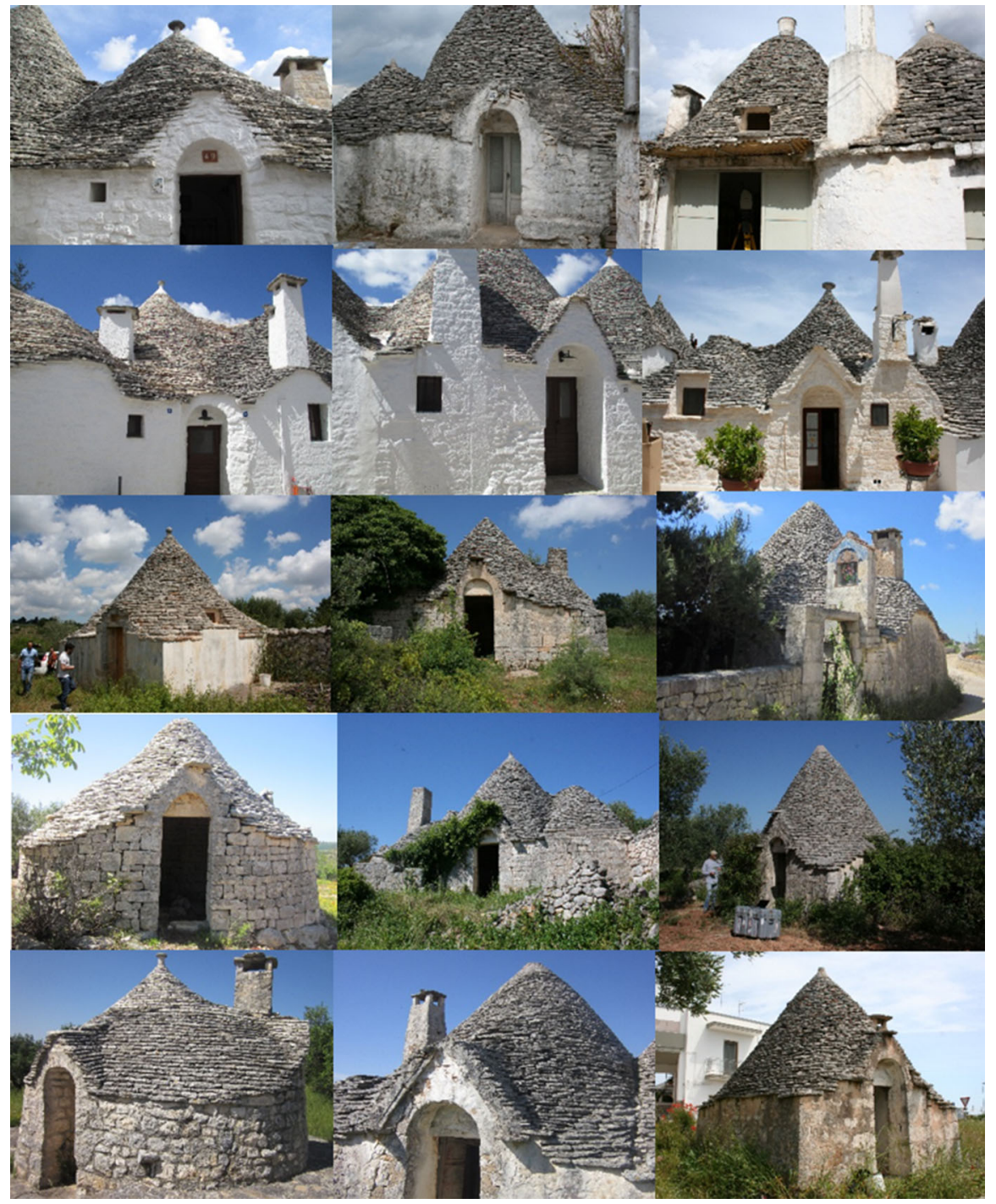

Fig. 3 An overview of the case studies (two of two) considered in the Apuliabase Project. The case studies belong to a wide range in terms of preservation conditions; both well-preserved and crumbling trulli were considered within the city centre (Alberobello) and its countryside

thickness and height of the lateral wall and structural profile of the dome. As far we know, it is the first time that geometric data are available for a large number of trulli.

In what follows we take full advantage of these data to perform a detailed analysis of the geometric features of trulli, currently missing in the literature. The first part presents an overview of the structural typology, together with an in-depth analysis of their peculiar and traditional building technique. The second part of the 
paper is dedicated to the analysis of the geometric parameters, collected from the in situ surveys of the thirty case studies. This includes a comparison in terms of internal force distribution between the geometry of an actual trullo and an idealised one.

\section{Building Typology}

\section{Vernacular Architecture}

Vernacular buildings are the result of a long construction tradition based on rules of thumb for the assemblage of stones to form a stable structure. Examples of drystone vernacular constructions are found in many parts of Europe, especially in Iceland, Ireland, Spain, Malta and Italy (Juvanec 2001; Löbbecke 2012). In the south of Italy, and particularly in the Apulia region, the vernacular dry-stone buildings belong to two main types: pagghiare (singular, pagghiara) and trulli. These two building typologies present different characteristics despite being located in areas that are only about 100 kilometres apart.

\section{Pagghiare}

Pagghiare are dry-stone structures located in the south of Apulia, specifically in an area that spans from the suburbs of Taranto and Brindisi to the Salento (Fig. 4). These areas are historically used for farming and do not provide the amount and quality of stones for the construction of high-quality masonry structures. Thus construction typology of pagghiare was developed by less proficient masons mainly for temporary storage of farming tools. The main features of this building typology are:

- absence of clusters with a resulting low building density over a given area;

- external geometry developed at several levels with circular sections that become smaller with the height (Fig. 4a);

- single enclosed space for each structure;

- vault or dome composed by the assemblage of semi-shaped stones or rough stones found on site;

- stones arranged following the semi-spherical dome geometry (Fig. 4b);

- soil used for the waterproofing of the dome.

\section{Trulli}

Trulli are mainly located in Valle d'Itria, an area between the cities of Bari, Taranto and Brindisi; within this limited area there are around 50,000 trulli (Giorgi and Speciale 1989). The word 'trullo' appears for the first time in a real estate contract of the 1796. It is still unclear whether the word trullo refers to the Latin word turris or trulla, or to the Greek word tholos, but the meaning is actually the same: dome. This architectural typology probably stems from the Mycenaean Tholoi built during 

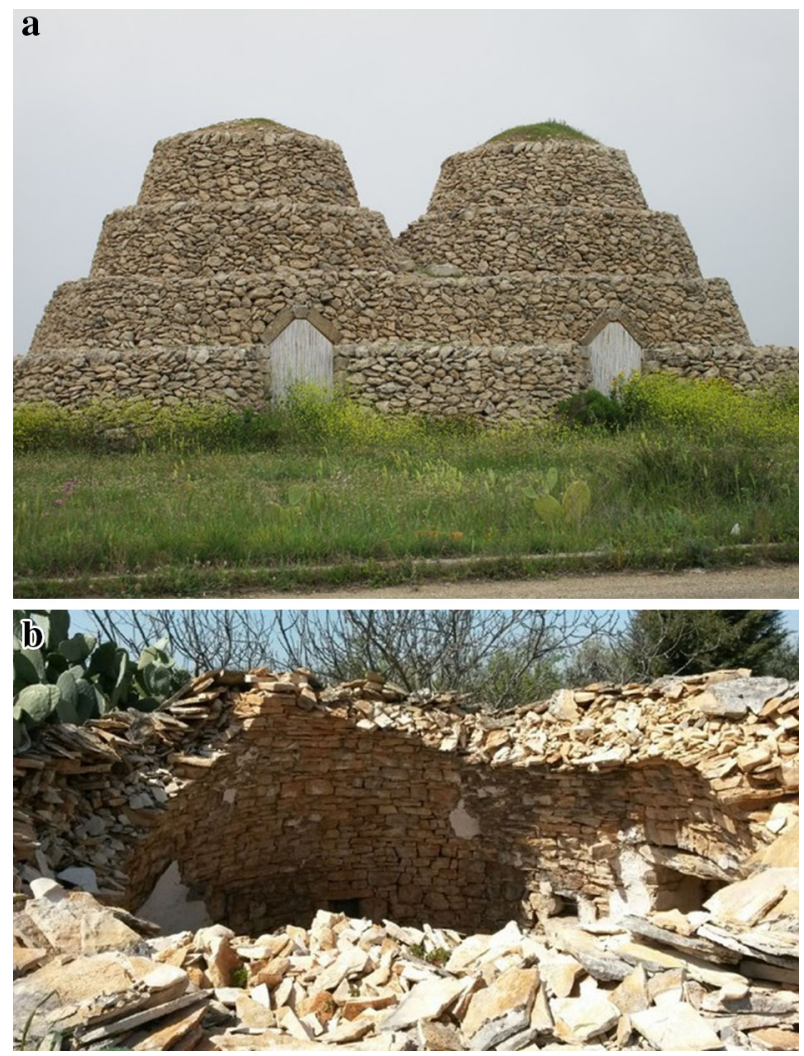

Fig. 4 Two examples of pagghiare, dry-stone vernacular constructions located at south of Apulia region. a external view of two pagghiare; $\mathbf{b}$ a cross-section of a pagghiara after its collapse

the Late Bronze Age (Cavanagh and Laxton 1981; Vernile 1996; Como 2006; Como 2007). While the tholos had a funereal use, trulli were and are addressed to many purposes that range from agricultural activities to housing, and currently to hotels, restaurants and local shops. The city of Alberobello (UNESCO World Heritage Site since 1996) is the town with the highest concentration of trulli (Fig. 5a). Trulli differ from pagghiare in terms of structure, functionality and architectural complexity. The main features of this building typology are:

- variable dimension of the main central space. The size is small for the use as storage unit while it becomes bigger and with the presence of alcoves when used as dwelling;

- quadrangular or circular section;

- distribution as clusters which depend on the surrounding environment (Ruggiero et al. 2013);

- single or plural cells (visible from the number of domes in one building) which form a complex structure with saddle connections between different domes. In 

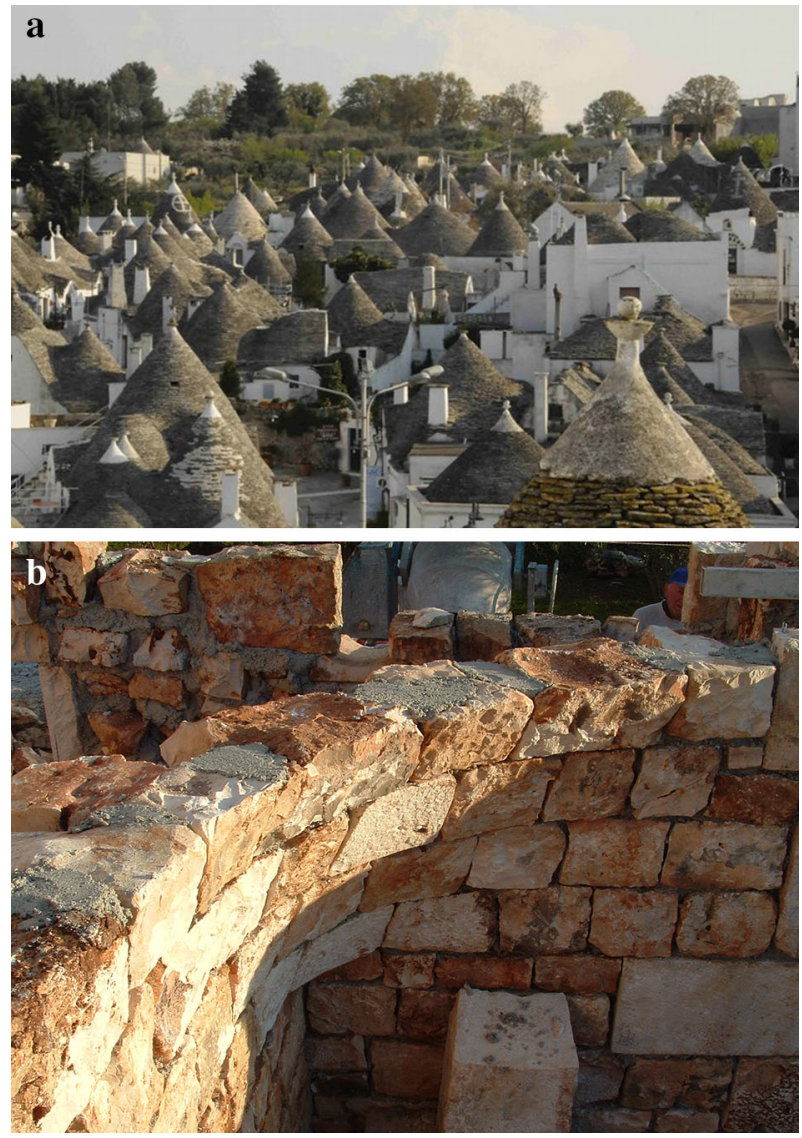

Fig. 5 Trulli are vernacular constructions mainly located in Valle d'Itria, an area between the cities of Bari, Taranto and Brindisi a an overview of Alberobello, the city with highest concentration of trulli; $\mathbf{b}$ a trullo during its construction

the Murgia dei trulli area $32 \%$ of the trulli are monocellular, $22 \%$ are bicellular, $30 \%$ have 3 or 4 cells and 16\% have more than 4 cells (Ruggiero et al. 2013);

- external pseudo-conical geometry;

- specific concave elements for the collection of rain water which also provide thermal insulation;

- well-shaped and hand-worked stones with different characteristics depending on their role and position in the structure;

- voussoirs in the dome arranged following horizontal rings with radii that decrease with height (Fig. 5b);

- trulli are still built today, while pagghiare are not.

These characteristics highlight the considerable evolution in terms of construction technique and point out the social, economic and cultural relevance of trulli. 


\section{Construction Technique of Trulli}

Trulli are built using a very simple technique that ensures a minimum level of workmanship on the material and, at same time, eliminates the need for temporary scaffolding for the construction of the dome. The result is a structure composed of thick double-leaf walls, which support a corbelled dome (Fig. 6). The building techniques adopted for constructing the basement and the dome are described in detail below.

\section{Lower Portion}

The lower portion of the building is composed by two main parts, the foundations and the wall, which usually have the same thickness and form a continuous vertical structure. The foundations lie beneath the ground level and they rest on a relatively stiff deposit (usually emergent calcareous rock). The wall is the upper part of the basement from the ground level to the dome.

The building process of the basement involves:

- the removal of the first layer of soil above the rock outcrop;

- the laying of the first course of stone blocks, which can have an irregular shape, forming the foundation of the structure; in the past, one or more adjacent rows of stone blocks were propped against each other on a poor mortar layer made with soil and water; this usually led to static pathologies that are still visible today in the form of cracks due to differential settlements;

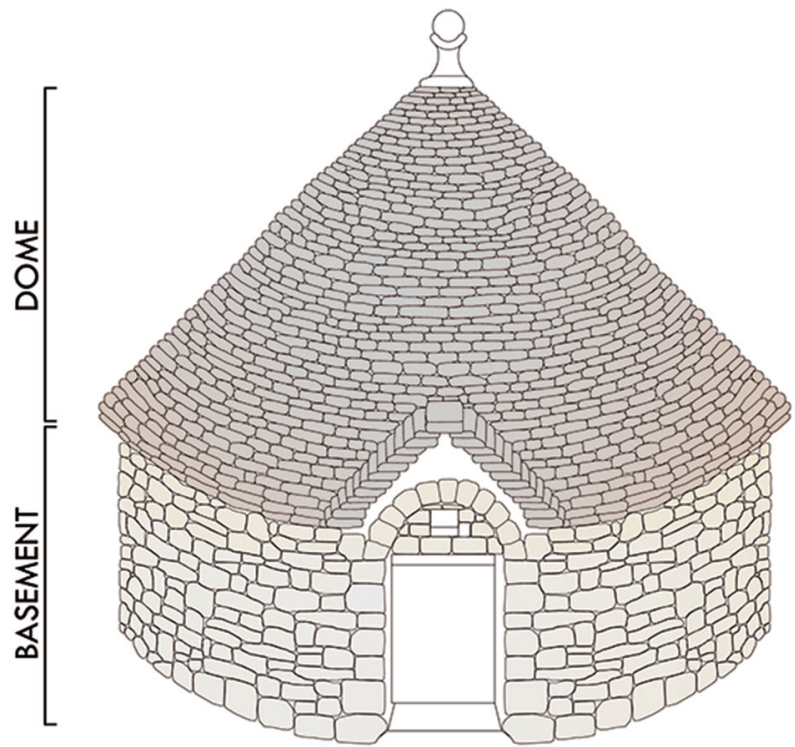

Fig. 6 Main elements composing trulli: a basement made of thick double-leaf walls and a corbelled dome 


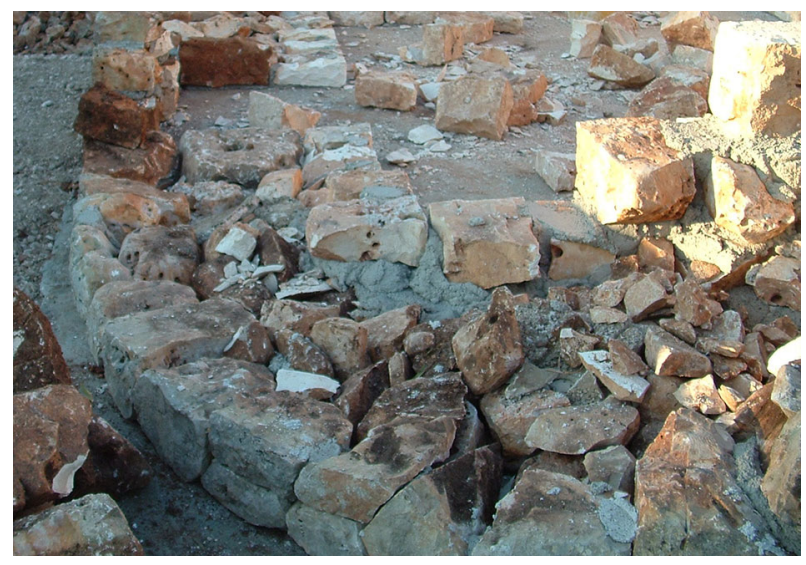

Fig. 7 Wall under construction. It consists of internal and external leaves of large and regular calcareous stones, with mortar poured between them

- the construction of the wall consists of internal and external leaves of large and regular calcareous stones, with the pouring of mortar and small stones between them (Fig. 7). The stone blocks composing the internal leaf are squared and well-shaped with regular surfaces, especially in dwellings. The outer leaf is composed by tapered stone blocks larger at the base. The wall's inner leaf bears the majority of the vertical load, and the double-leaf wall resists the out-of-plane action of the horizontal thrust exerted at the springing line by the dome.

\section{Dome}

The upper portion of a trullo is represented by the dome. As shown in Fig. 8, a vertical section of the dome is composed of three main parts: the candela (plural, candele), stones with a structural function; insulating filler; chiancarelle, masonry cladding.

The candela supports the whole dome, and its construction follows a unique procedure that eliminates the use of temporary supports. The height of the starting course (i.e., the springing line) of the candela is established by the master builder by locating four main blocks at the corners of the quadrangular section of the basement (Fig. 9); these will guide the construction throughout. Today, depending on the skill of the trullaro, the construction can be done with or without mortar.

The height of the starting level of the candela depends on the characteristics of the enclosed space. In particular, the presence of openings and archways brings about a complicated set up of the intersecting blocks where they meet the candela, leading to complicate arrangements of the first courses of blocks. For instance, when an architrave or an archway is close to the corner, the trullaro has to arrange a single stone course in such a way that it complies with two different static paths: the arch and the pseudo-horizontal ring of the dome (Fig. 10). 

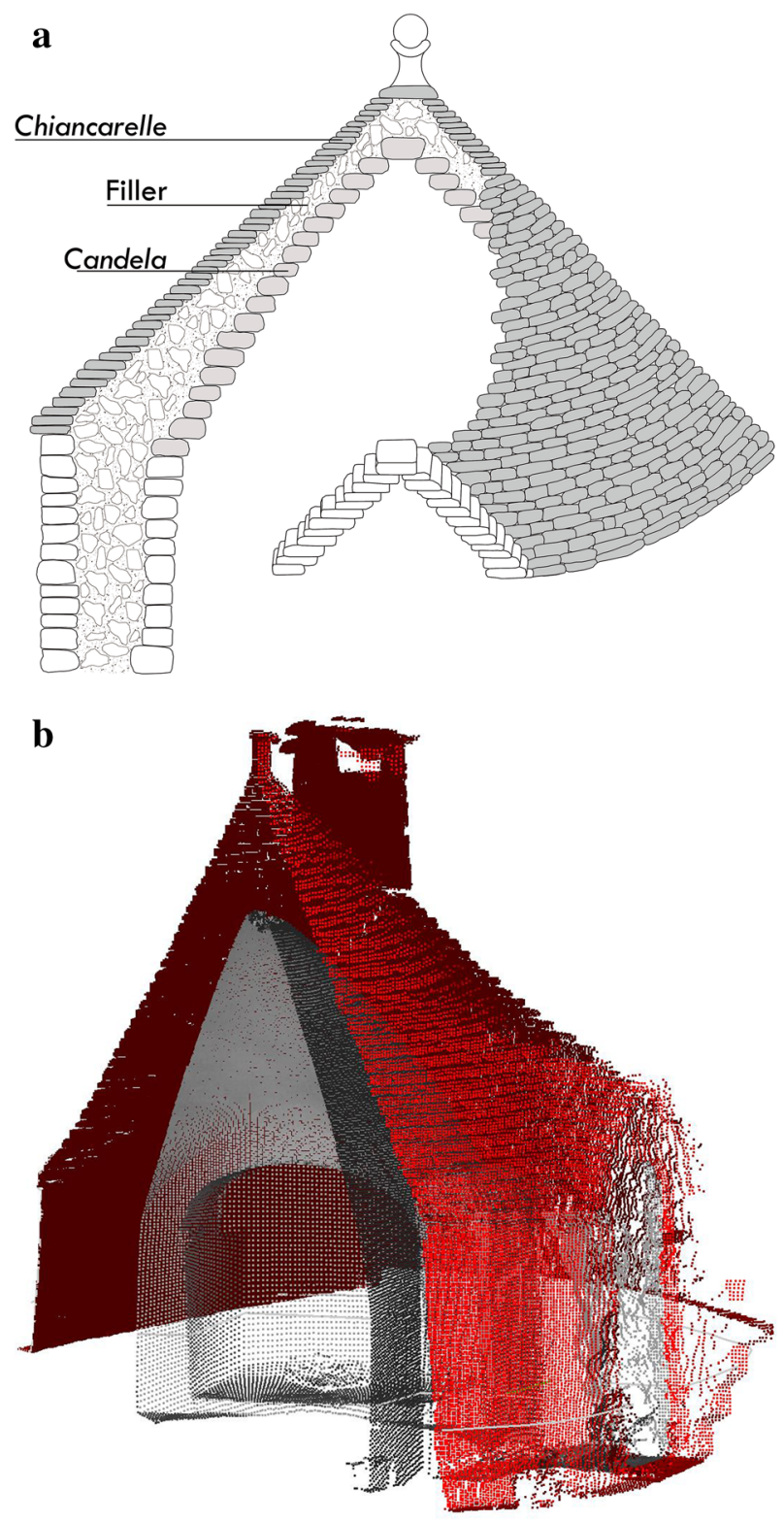

Fig. 8 a Vertical section of the dome. It is composed of three main parts: stones with a structural function (candela), insulating filler and masonry cladding (chiancarelle) showing the three main parts; b high-fidelity 3D model of a trullo

The construction technique of the dome foresees the overlapping of the jutting horizontal rings in progression. The corbelling construction technique requires a self-supporting structure in order to mobilise the hoop forces and ensure equilibrium. Figure 11 shows an example of a corbelled construction: the inclusion 


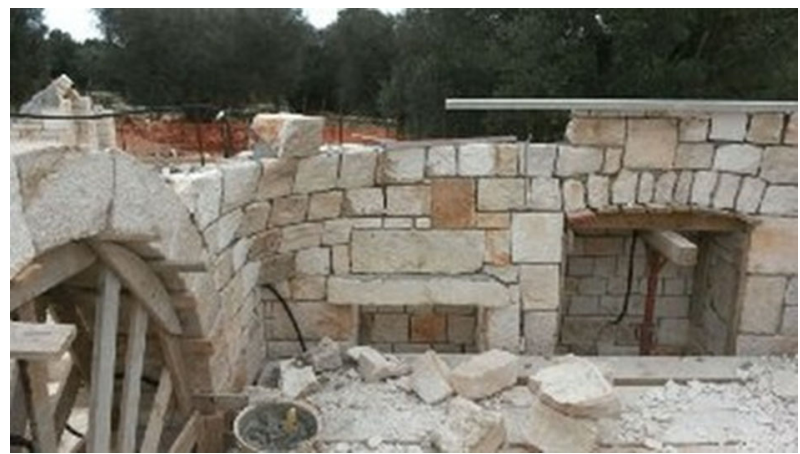

Fig. 9 Corner blocks to guide the construction of the candela

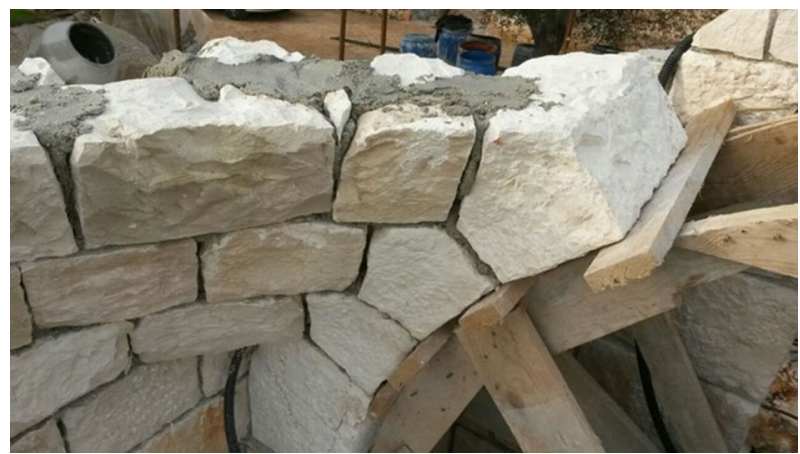

Fig. 10 Detail of a corner, where the stones complies with two different static paths: the arch and the pseudo-horizontal ring of the dome

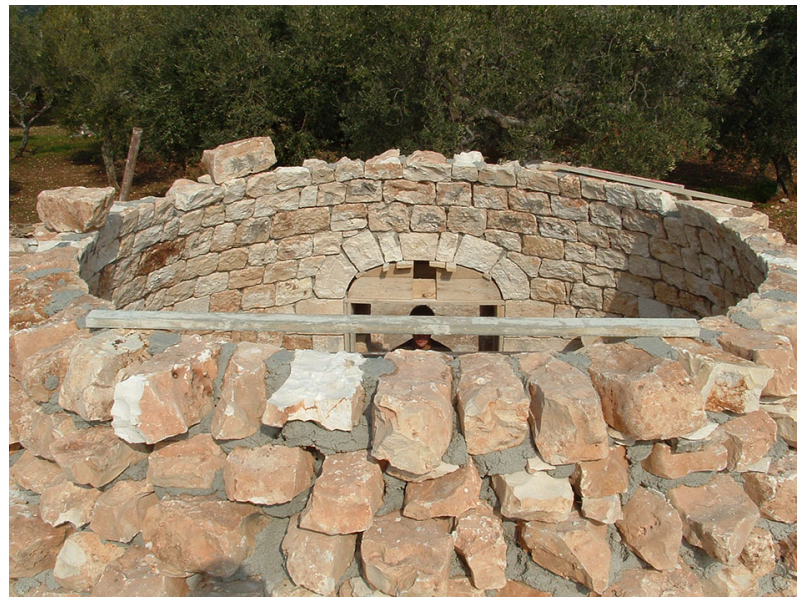

Fig. 11 Construction of the candela without centring: the inclusion of small stones (scarde) and/or, more recently, mortar guarantee the continuity of the horizontal rings 


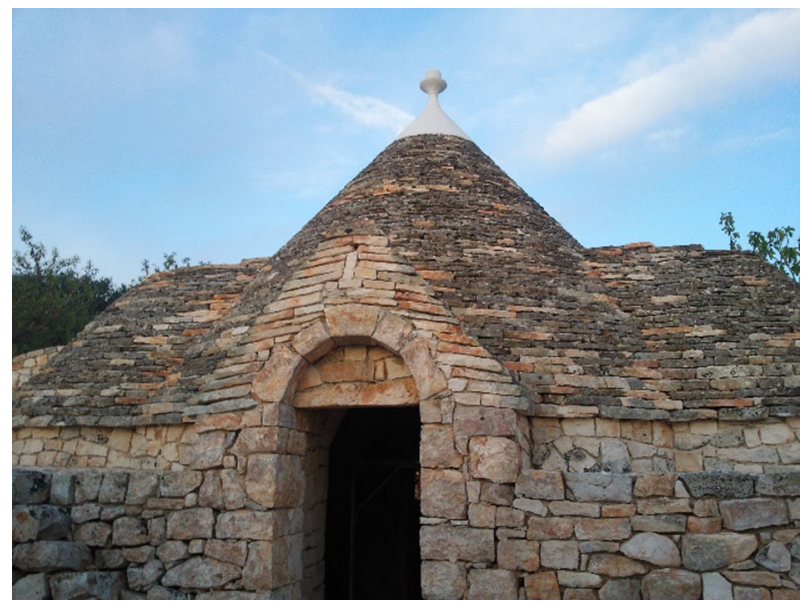

Fig. 12 Roof cladding made of chiancarelle to facilitate the water drainage

of small stones (scarde) and/or, more recently, mortar guarantee the continuity of the horizontal rings. In some cases, the trullaro shapes the inner surface of the candela in order to make the edges of the rings protrude, thereby forming a smooth and well-finished surface that resembles that of classical masonry domes.

After laying the filler, the finishing of the trullo ends with the completion of the roof with the coating of chiancarelle (singular, chiancarella) and the installation of the distinctive pinnacle at the crown (Fig. 12). Chiancarelle are thin $(3-7 \mathrm{~cm}$.) slabs of limestone. They are placed on the exterior of the dome, and in particular on the filling material with an outward slope in order to facilitate the water drainage. The roof cladding is laid down without any use of mortar in order to facilitate the aeration of the structure.

The analysis of the collapse mechanisms of several existing and damaged trulli identified the dome as the structural element most vulnerable to external actions. The analysis of their structural behaviour has been presented in more detail elsewhere (Sanitate et al. 2014; Todisco and Sanitate 2016). In summary, trulli work as a combination of corbelling in section and hoop forces in plan, as already reported by Edward Allen (1984). In the majority of cases, forces acting on each voussoir cannot be considered coplanar. As described before, the inclusion of small stones (scarde) between main stones of the candela enables load paths along both horizontal masonry rings and vertical arches.

\section{Dome Morphology}

The survey of thirty existing trulli located in and around Alberobello highlights differences in terms of their geometry. The candela, previously identified as the most structurally vulnerable element of a trullo, is the object of the following analysis. Figure 13 illustrates the different morphologies (shape and thickness) of the candele of the surveyed trulli. 

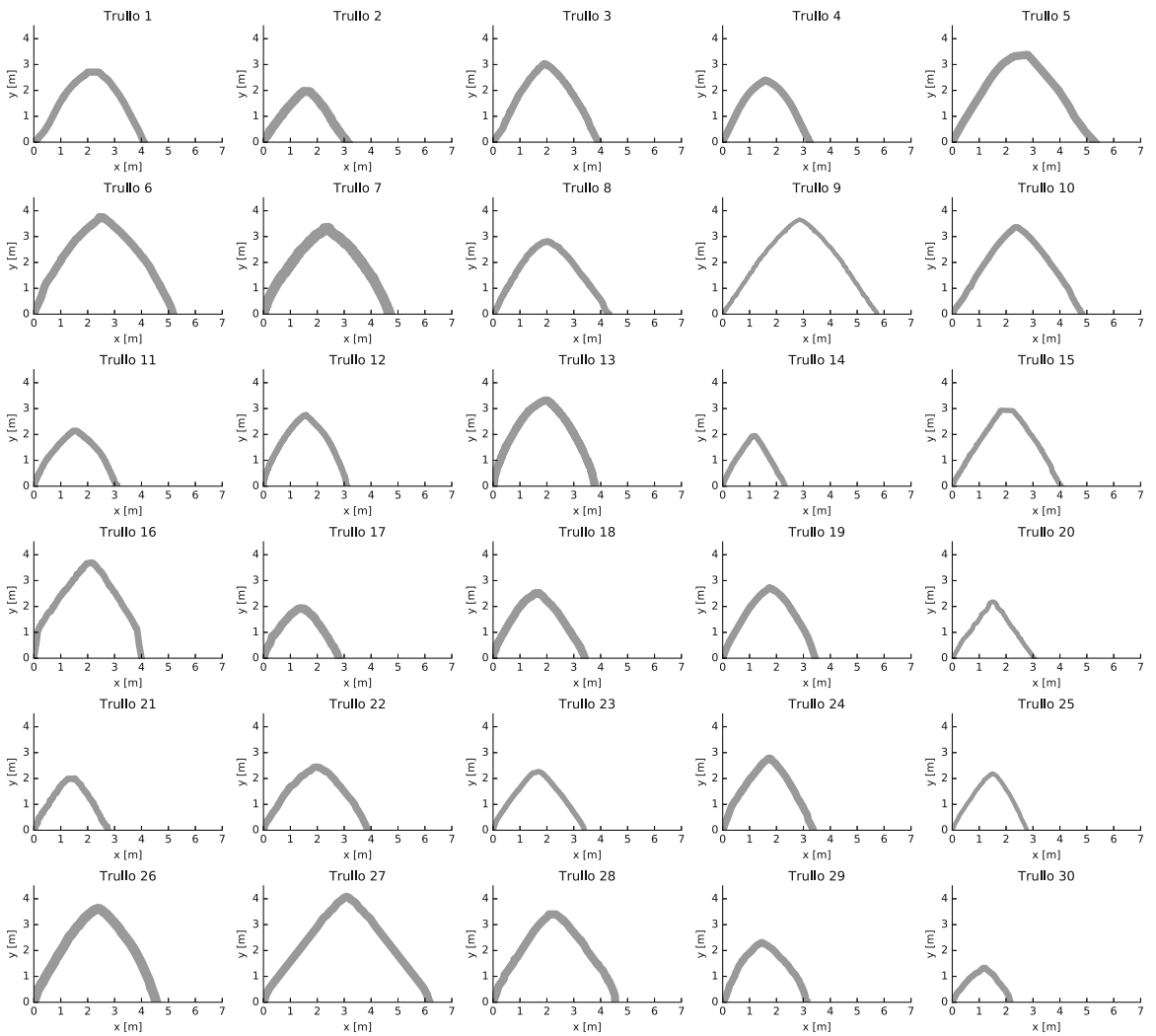

Fig. 13 Morphologies of the candela for surveyed trulli

The span and the height of the candele are considerably variable. Moreover, there is no correlation between thickness and span. For instance, the thickness of the candela of trullo 9 is only three-quarters that of trullo 7 , even though its span is greater.

In what follows we show, by means of histograms, of the geometrical parameters among the thirty trulli considered in this analysis. Figure 14 shows the distribution of the number of the trulli according to the height of the candela subdivided in class intervals of $1 \mathrm{~m}$. Notice that most of the trulli (97\%) in the database have a height less than 4 metres, and that the majority of these (80\%) range between 2 and $4 \mathrm{~m}$.

Next, in Fig. 15 the number of trulli is plotted according to the diameter (i.e., internal span) subdivided in class intervals of $1 \mathrm{~m}$. The peak of the distribution for thirteen domes (43\%) lies between 3 and 4 metres, and the 93\% of trulli (i.e., twenty-eight buildings) have a diameter less than 5 metres. One exceptional example of large span between 6 and 7 metres is reported, representing only the $3 \%$ of the entire set. The relatively small dimension of trulli leads to issues for the renewal of their functionality that currently requires high standards of comfort for accommodation and hotels. 


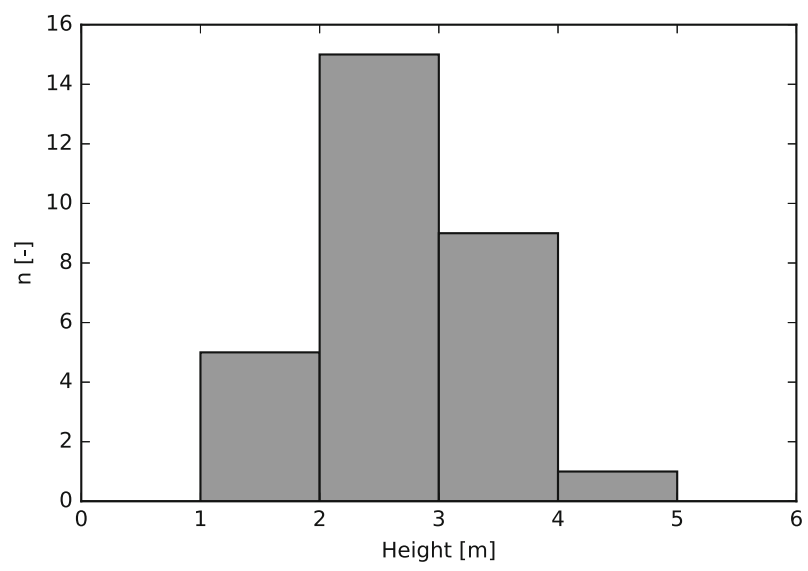

Fig. 14 Number of trulli plotted according to the height of the candela

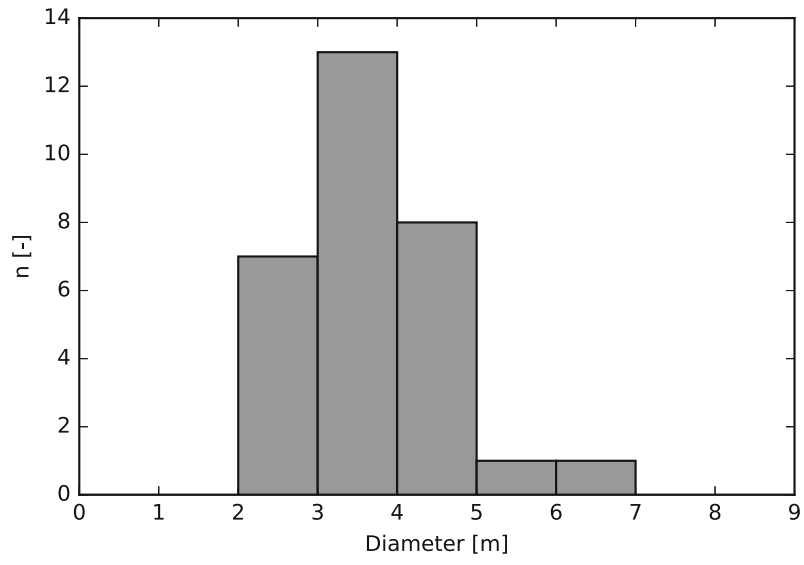

Fig. 15 Number of trulli plotted according to the diameter of the candela

The distribution of candela thickness is plotted in Fig. 16 subdivided in class intervals of 0.05 metres. The majority of candele (73\%) have a thickness between 0.2 and 0.3 metres. There are no trulli in which the candela thickness is less than 0.15 metres.

Figure 17 shows the comparison between the actual profile (solid line) of the candele and the idealised parabolic (dotted line) and conical (dashed line) profiles. For each trullo analysed, the difference in terms of $\mathrm{R}^{2}$ between the actual geometry of the candela and the aforementioned idealised curves is indicated. $R^{2}$ is a statistical value that indicates how close the real data are to a defined curve (a $\mathrm{R}^{2}=1$ indicates a perfect match).

The actual profile of candele does not fall consistently within either the conical or the parabolic category. While the shape of a number of candele can be regarded as conical (trulli 10, 15, 20 and 27 with $\mathrm{R}^{2}>0.98$ ), in other cases there seems to be a 


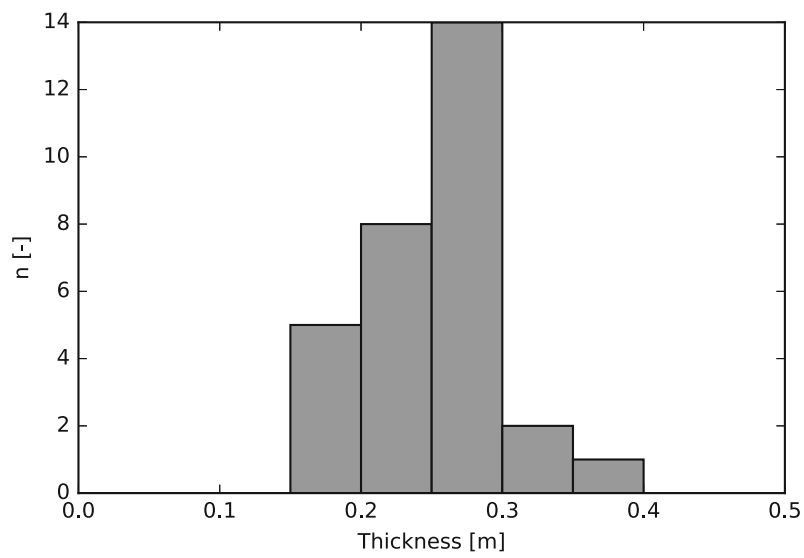

Fig. 16 Number of trulli plotted according to the thickness of the candela

considerable difference (trulli 13 and 16 with $\mathrm{R}^{2}<0.6$ ). A similar conclusion can be drawn for the idealised-parabolic shapes: for a few trulli the two curves are similar (trulli 13 and 18 with $\mathrm{R}^{2}>0.98$ ), while in other cases (trulli 15 and 20 with $\mathrm{R}^{2}>0.80$ ) the difference is significant. The statistical analysis of $\mathrm{R}^{2}$ for the 30 domes previously analysed yield the following values:

\begin{tabular}{lll}
\hline & Pseudo-conical shape & Pseudo-parabolic shape \\
\hline Mean value & 0.875 & 0.899 \\
Standard deviation & 0.107 & 0.081 \\
Coefficient of variation & 0.122 & 0.091 \\
\hline
\end{tabular}

Our main conclusion is that despite the apparent external conical shape of the building, the candela, which is responsible for the safety of the dome, has a geometry that might strongly differ from both the cone and the elliptic paraboloid, lying effectively between the two.

\section{Effect of Geometry on Internal Force Distribution}

As mentioned before, the geometry of a masonry structure plays a key role in the internal force distribution, and, consequently, on the safety of such structures. In what follows we will estimate the difference, in terms of internal force distributions, between an actual trullo and a trullo with an idealised conical candela.

By using an approach based solely on equilibrium it is possible to find a threedimensional equilibrated network of forces in which both the meridians and parallels are activated (Lau et al. 2010). The meridian load paths within the structure and directed from the key stone to the basement walls, can be approximated by polygonal lines; in general, horizontal thrusts are generated at each deviation node of the load path. These horizontal thrusts are responsible for activating ring load 

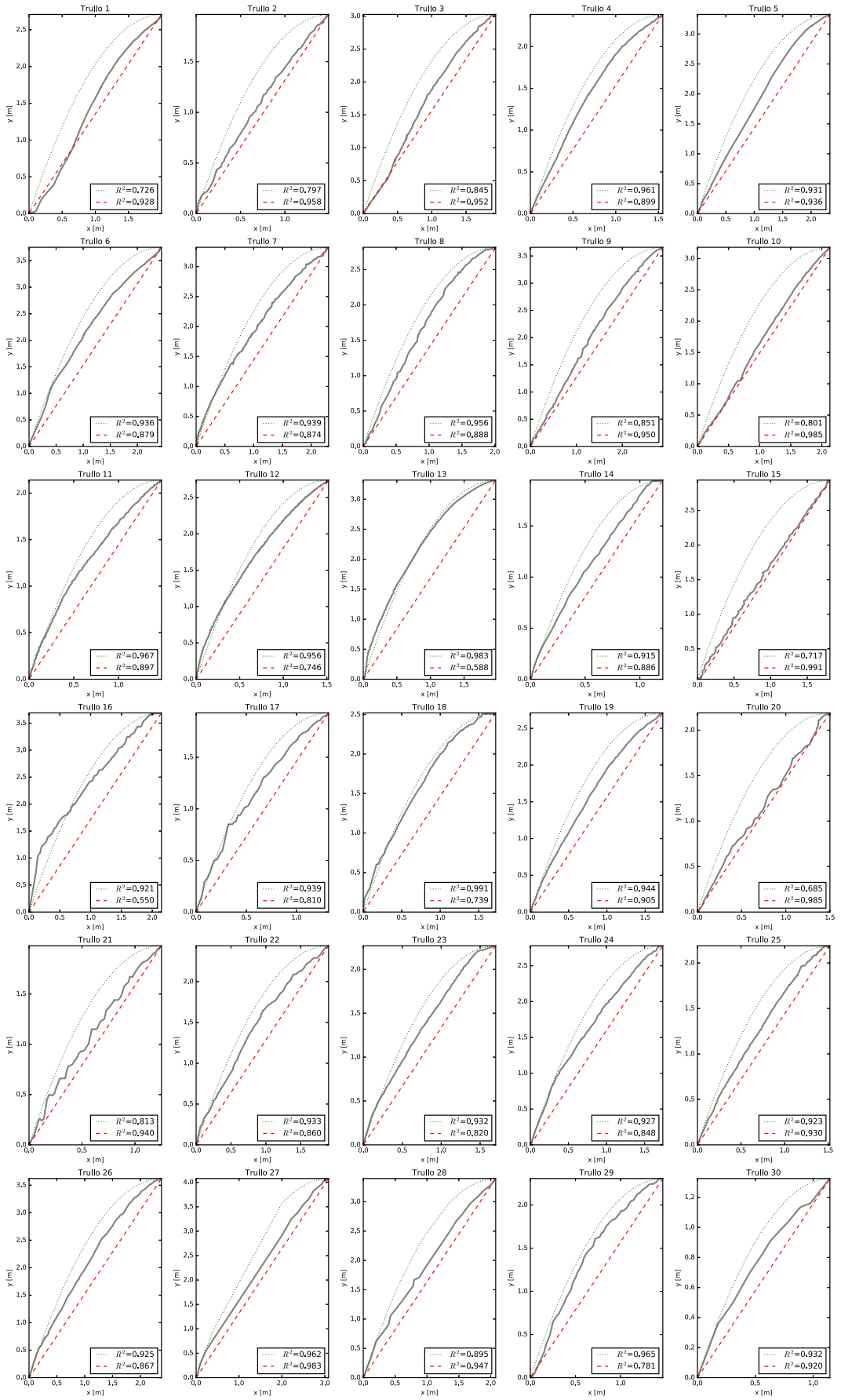

Fig. 17 Comparison between real and idealised-conical and -parabolic shapes of the candela for 30 trulli 
paths. For a dome with an arbitrary shape, these horizontal thrusts can be inward or outward, generating, respectively compressive and tension forces within the ring.

Due to the indeterminate nature of masonry domes, infinite equilibrated thrust surfaces can be found inside the vault thickness guaranteeing its stability. As proposed by Maria Teresa Como for the Mycenaean tholoi (2006; 2007), a possible strategy for simplifying the problem is to force the meridional thrust line to pass through the dome's centreline. As a result, the meridional and ring forces, composing the equilibrated force network, are determined by defining the exact position of the deviation node.

Using this assumption, a study has been performed on the trullo 13. Its candela, as shown in Fig. 15 , presents a $\mathrm{R}^{2}=0.59$, which indicates a significant difference between its shape and an idealised conical dome.

Figure 18 shows the internal force distribution for the actual geometry (on the left) and the conical dome (on the right) through graphic statics (Culmann 1864; Cremona 1872; Allen and Zalewski 2009; Fivet and Zastavni 2013; Todisco et al. 2016). The slopes of the thrust line segments in the shape polygon are equal to the slopes of the meridional force vectors in the force polygons. The geometric idealization of the candela's shape is based on the same span, height, thickness and total dead load of the real one. Furthermore, the dome has been divided into simple arches with constant depth.

The force diagrams of Fig. 18 clearly illustrate differences between the two shapes in terms of internal force distribution. While the idealised shape presents a linear increment of axial forces through the meridians, the actual shape shows a variable increment of compressions moving from the key stone to the basement walls. Furthermore, the horizontal thrust generated at each deviation point has a constant magnitude and direction in the idealised shape (all rings are equally compressed), whereas the horizontal path in the real dome works in compression or in tension depending on the deviation node in question. Consequently, given that the structural vulnerability of a masonry structure depends on the internal force

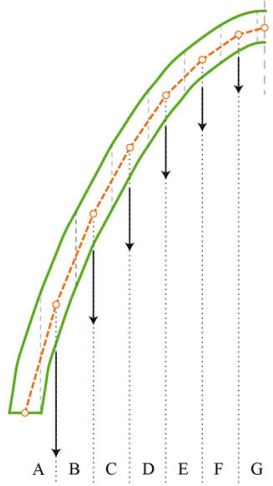

FORM DIAGRAM

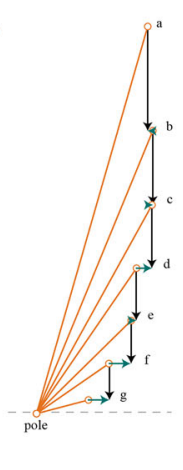

FORCE DIAGRAM

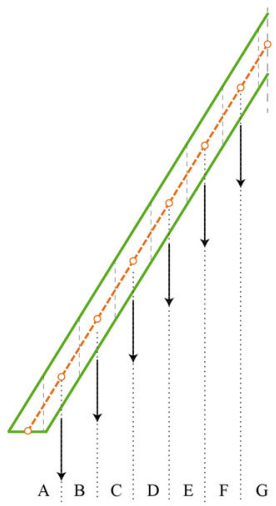

FORM DIAGRAM

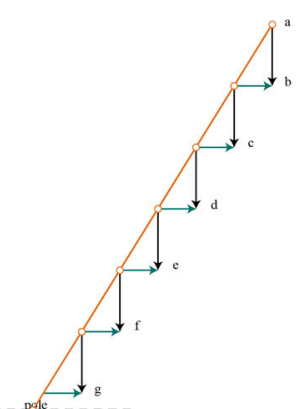

FORCE DIAGRAM

Fig. 18 Comparison between form and force diagrams of the actual shape of a candela (left) and a conical-idealised one (right) 
distribution, results may be strongly affected by the geometry adopted in the analysis.

Because of the simplifying assumptions, this analysis cannot represent a complete study for evaluating the effects of adopting an idealised dome profile instead of the actual one. Nevertheless, it clearly illustrates that assuming a conical shape of the candela is not sufficient for a preliminary assessment of its structural behaviour and can lead to incorrect results. A more in-depth analysis of the geometrical profile of the candela, by means of integrated survey techniques (i.e., laser scanner and geo-radar), is required for the structural analysis of trulli.

As future research, the same study on the assumption of the candela's profile (Fig. 18) may be extended to all the case studies. The analysis of the candela may involve different meridional thrust lines not constrained to the centreline of the dome, a more precise distribution of loads (including super-imposed loads) and a variable depth of the lunes in which the dome is divided.

\section{Dome Proportions}

This section presents a general overview of the main proportions of trulli domes. Figure 19 shows the distribution of the candela's thickness in relation to its height. Generally speaking, one would expect an increase of the candela's thickness with its height in order to accommodate the higher compressive stresses in the material. However, the results show that there is no correlation between height and thickness of the candela.

In Fig. 20, the thickness of the candela is plotted according to its corresponding diameter. There is no relation between the two parameters, even if a relationship between diameter and thickness should be expected (higher loads should require greater thickness). It appears that, although the construction technique of trulli is well-established, the choice of the structural blocks constituting the structural dome is based merely on the judgement of the trullaro rather than relying on solid engineering concepts.

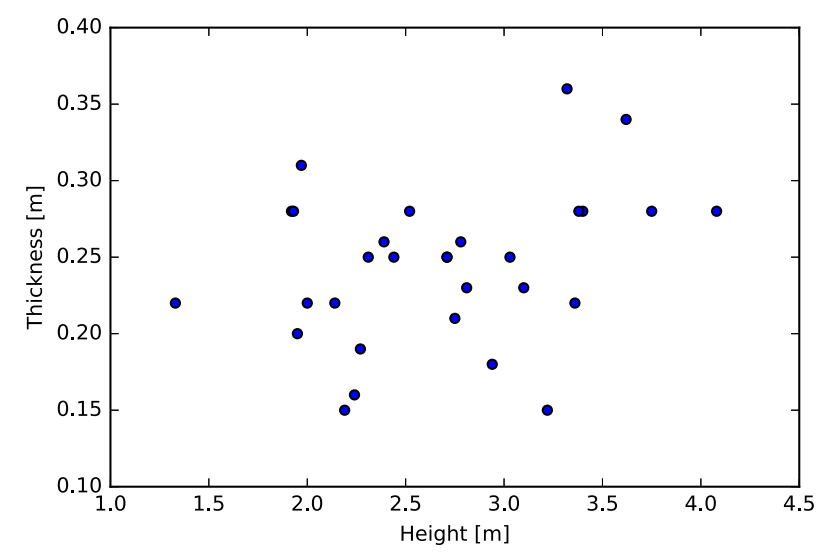

Fig. 19 Distribution of the thickness according to the height for the 30 surveyed trulli 


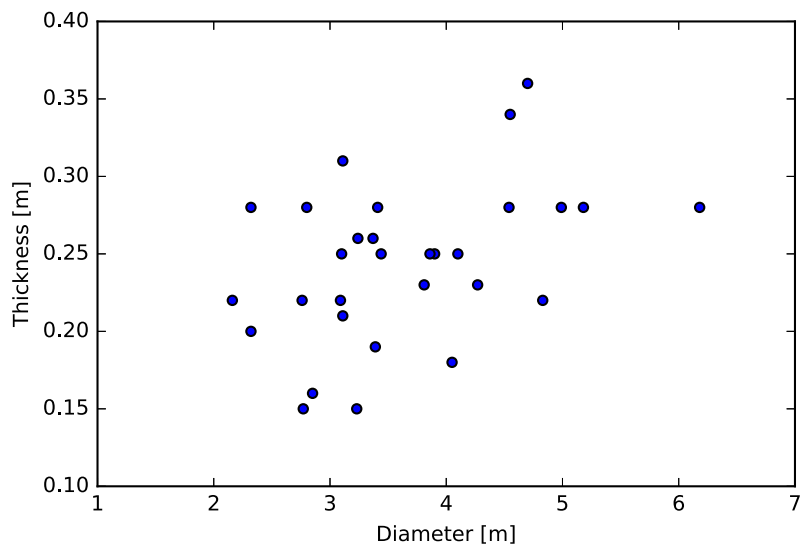

Fig. 20 Distribution of the thickness according to the diameter for the 30 surveyed trulli

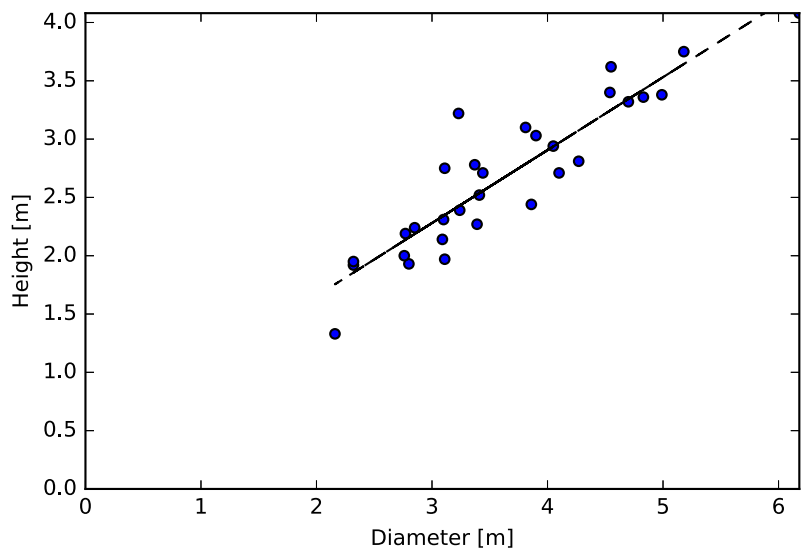

Fig. 21 Distribution of the height according to the diameter for the 30 surveyed trulli

The relation between the height and the diameter is plotted in Fig. 21. This plot shows a clear trend of the height of an increase in height as the diameter of the candela increases. The slope of the linear regression is around $40^{\circ}\left(\mathrm{R}^{2}=0.83\right)$, indicating that the diameter of the dome is commonly around the $80 \%$ of the height.

\section{Conclusions}

This paper has presented a brief historical review of trulli, together with a detailed description of their building typology and construction technique. Given the availability of collected data for 30 case studies, it was possible to investigate the main geometrical parameters and proportions of trulli located in and around Alberobello. The main conceptual remarks can be outlined as follows: 
- trulli differs from other dry-stone building typologies (e.g., pagghiare) in terms of construction technique, spatial distribution in clusters, combination of more than one enclosed space (cell). Trulli represent a unique typology of architectural heritage that deserve special attention in terms of conservation;

- trulli have different geometrical parameters that, in general, do not derive from engineering concepts. They differ considerably in terms of span and height. The majority of the analysed buildings have an internal height between 2 and $4 \mathrm{~m}$, and an inner span ranging from 2 to 5 metres;

- the thickness of the candela is not related to either the span or the height; this suggests that the construction technique is based on rules of thumb and the judgement of the master builder rather than being based on fundamental engineering science;

- the geometry of an individual trullo cannot be obtained by simplifying assumptions (e.g., thickness proportional to the span) and should be retrieved through geometric surveys prior to any structural assessment;

- the candela tends to have a span proportional to its height; its shape can be more or less similar to a cone depending on the trullaro's construction technique;

- the commonly adopted assumption of idealising a candela with a conical dome or an elliptical paraboloid dome may be inadequate for a preliminary assessment of structural vulnerability and can lead to incorrect results.

The geometrical data and proportions presented in this paper refer to a set of 30 trulli located in Alberobello. They represent a unique reference for the literature in the field of vernacular structures, representing benchmark geometries for future research on the topic.

Acknowledgement All images and photos shown here are by the authors.

\section{Bibliography}

Allen, Edward. 1984. Pietre di Puglia: dolmen, trulli e insediamenti rupestri. Bari: Adda.

Allen, Edward and Waclaw Zalewski. 2009. Form and Forces Designing Efficient, Expressive Structures. New York: John Wiley \& Sons.

Ambrosi, Angelo, Panella, Raffaele and Giuseppe Radicchio. 1997. Storia e destino dei trulli di Alberobello: prontuario per il restauro. Fasano di Brindisi: Schena.

Cavanagh, William, and Robert Laxton. 1981. The Structural Mechanics of the Mycenaean Tholos Tombs. Annu Brit Sch Athens 76: 109-140.

Como, Maria Teresa. 2007. L'architettura delle "Tholoi" micenee: aspetti costruttivi e statici. Napoli: Università degli studi Suor Orsola Benincasa.

Como, Maria Teresa. 2006. Analysis of the Statics of Mycenaean Tholoi. In: Proceedings of the Second International Congress on Construction History, eds. J. Campbell M. Dunkeld H. Louw, M. Tutton, B. Addis, C. Powell, R. Thorne, 777-790. Cambridge: Exeter.

Cremona, Luigi. 1872. Le figure reciproche nella statica grafica. Milano: Tipografia di G. Bernardoni. Culmann, Karl 1864. Die graphische Statik. Zürich: Verlag von Meyer and Zeller.

Fivet, Corentin and Denis Zastavni. 2013. Constraint-based graphic statics: New paradigms of computeraided structural equilibrium design. Journal of the International Association for Shell and Spatial Structures 54: 271-280.

Giorgi, Carla. and Paolo Speciale. 1989. La cultura del trullo. Antologia di scritti letterari e scientifici sui trulli. Fasano: Schena Editore. 
Heyman, Jacques. 1995. The Stone Skeleton: Structural Engineering of Masonry Architecture. Cambridge; New York: Cambridge University Press.

Huerta-Fernández, Santiago. 2008. The Analysis of Masonry Architecture: A Historical Approach. Architectural Science Review 51: 297-328.

Juvanec, Borut. 2001. Six thousand years, and more, of corbelling, age of stone shelters. In Proceedings of UNESCO/ICOMOS Congress I. Paris: UNESCO/ICOMOS.

Lau, Wanda, John Ochsendorf, and Jennifer Zessin. 2010. Equilibrium of cracked masonry domes. Proceedings of the ICE - Engineering and Computational Mechanics 163: 135-145.

Löbbecke, Renate. 2012. Corbelled domes. Köln: Verlag der Buchhandlung Walther König.

Ruggiero, Giuseppe, Dal Sasso Stefano, Loisi Rosa Viviana, and Giuseppe Verdiani. 2013. Characteristics and distribution of trulli constructions in the area of the site of community importance Murgia of Trulli. Journal of Agricultural Engineering. PAGEPress Publications: e13.

Sanitate, Giuseppe, Leonardo Todisco and Giuseppe Monti. 2014. Effective assessment methodology for trulli in Apulia, Italy. In Proceedings of 9th International Masonry Conference. Guimares.

Todisco, Leonardo, Corres-Peiretti Hugo and Caitlin Mueller. 2016. Funicularity through External Posttensioning: Design Philosophy and Computational Tool. Journal of Structural Engineering 142: 1-9. doi:10.1061/(ASCE)ST.1943-541X.0001416.

Todisco, Leonardo and Giuseppe Sanitate. 2016. Static stability of trulli. Materials and Structures 49: 2893-2905. doi:10.1617/s11527-015-0693-4.

Vernile, Brunella. 1996. Los trulli. In Historia de la Construcción (Actas del Primer Congreso Nacional, Madrid, 19-21 Sept. 1996), Santiago Huerta Fernández and Enrico Rabasa Díaz, eds., 515-523. Madrid: Instituto Juan de Herrera, CEHOPU: Casas Gómez.

Leonardo Todisco is a structural engineer at FHECOR Consulting Engineers and a researcher at the Technical University of Madrid, Spain. He earned a Ph.D and a M.Eng. in Structural Engineering from the Technical University of Madrid, Spain, and a M.Sc. and a B.Sc. in Civil Engineering from the Technical University of Bari, Italy. His research interests include shear strength of reinforced concrete members, masonry structures and conceptual design of structures. He was awarded the 13th IASS Hangai Prize. Leonardo is co-founder of Apuliabase, a start-up working on the conservation, analysis and restoration of the Architectural Heritage.

Giuseppe Sanitate is currently a $\mathrm{PhD}$ candidate at the University of Cambridge. His interest lies primarily on the dynamic response of buildings to ground-borne vibration. He holds a M.Sc in Earthquake Engineering from the MEEES Erasmus Mundus programme, and a MSc. and a B.Sc in Civil Engineering from the Technical University of Bari, Italy. Giuseppe is co-founder of Apuliabase, a start-up working on the analysis and conservation of Architectural Heritage.

Giuseppe Lacorte works as trullaro (trullo master builder) and master mason of dry-stone and traditional vernacular structures. He was a student at the University of Bari, but he left academia to be full-time dedicated to the construction of masonry structures. He is involved in the study of stereotomy and its application to new masonry structures. He is currently engaged in the design and construction of a large cluster of trulli and vaulted structures. 